\title{
Reforma beneficial en Palencia a fines del Antiguo Régimen
}

\author{
M.P. Almudena Garcia Herreros
}

La reforma beneficial es el intento por parte de la Corona de mejorar aquella parte de los bienes del clero que estaban vinculados a cargos $u$ organismos eclesiásticos, pertenecían a la Iglesia como institución y la participación de sus miembros se producía como contraprestación al desempeño de unas funciones. Habia una gran diferencia entre parroquias e incluso dentro de ellas. Estos objetivos hay que enmarcarlos dentro de la politica reformista e ilustrada que se realizó durante el reinado de Carlos III.

El punto de partida se encuentra en la firma, en 1753, de un concordato entre la monarquía española y Roma. Con su aprobación no se solucionó todo el contencioso entre el Estado español y la Santa Sede, ni se transfirieron al monarca plenas facultades de control sobre toda la Iglesia, lo que si se logró fue la supresión de las reservas pontificias, es decir, la capacidad que tenía la Santa Sede de nombrar las vacantes de puestos eclesiásticos y percibir sus frutos. Desde este momento dicha prerrogativa pasaba a la Corona.

El papa, para evitar una rupturá, accedía a que la Corona de España nombrase las vacantes de arzobispados, obispados y beneficios consistoriales (los que nombraba el papa en reunión con sus obispos) de España e Indias, durante los meses reservados ${ }^{1}$ sustituyendo a la Santa Sede. Respecto a los demás beneficios ${ }^{2}$ se reconocia el derecho de denominación que pretendian los reyes de España, reservándose el papa y sus sucesores el nombramiento de 52 beneficios no consistoriales distri-

Los meses reservados eran cuatro: marzo, junio, septiembre y diciembre.

${ }^{2}$ El beneficio era un cargo eclesiástico de rango inferior al sacerdote, cuya misión era colaborar con éste on las tareas parroquiales. 
buidos en 29 diócesis. El concordato también suprimia la presentación alternativa a la Santa Sede que gozaban los obispos y los patronos.

Las disposiciones acordadas no comportaban ningún perjuicio a las facultades del ordinario o de los patronos que conservaban sus meses de presentación. No se concedia ninguna jurisdicción eclesiástica sobre las iglesias o los clérigos. Todos los beneficios que conllevaban cura de almas ${ }^{3}$ serían provistos en lo sucesivo por sorteo.

Para realizar estas medidas contempladas en el concordato se desarrolló el plan beneficial. Éste se puso en práctica mediante las circulares del Consejo de Castilla del 5-7-1758 y 12-6-1769, extendido a los territorios dependientes de las órdenes militares por decreto 26-6-1771. En elias el Consejo solicitó a los prelados la elaboración de unas listas en las que enumerase los beneficios insuficientemente dotados proponiendo su unión, agregación o supresión.

Los planes especificarian las medidas tomadas en cada parroquia: su población, la distancia de las poblaciones vecinas cuando estuviese prevista la división de las mismas, el status, régimen de presentación de los puestos, rentas fijas y eventuales, así como las cargas temporales y espirituales de cada cargo eclesiástico: beneficio, curato o capellania. Todo esto se sometería a la sanción regia previo examen del Consejo de Castilla.

Las reformas se realizarian, en la medida de lo posible, respetando los iimites parroquiales, así como puestos de la misma naturaleza y régimen de presentación. Se pondrian en práctica a la vacante de los puestos afectados, respetando a sus actuales poseedores.

El objetivo prioritario fue el aumento del número de curatos, asegurando a sus titulares el sustento necesario para atender las obligaciones y poder ayudar a los feligreses en momentos de necesidad. Se establecieron dotaciones para cada puesto, uniformes dentro de la diócesis, o diferentes cuando las necesidades locales asi lo exigian. En la mayoria se produjo un aumento del número de curatos al tiempo que descendia el de capellanes y simples beneficiados, hubo también una revalorización de curas y vicarios.

En 1783, en un balance de la reforma beneficial, se puso de manifiesto la extremada lentitud con que se estaba realizando, debido a la coexis-

Según el Diccionario de autoridades, Madrid, $3^{\mathrm{a}}$ Reimpr. 1976, T. 1, p. 705, la cura de almas es la «Obligación que tiene el párroco de administrar y explicar la Doctrina Cristiana a los Feligreses". 
tencia de dos administraciones y al estudio pormenorizado que realizó el Consejo de los recursos presentados por las corporaciones y particulares que se sintieron perjudicados. Para agilizar el proceso los reformadores debieron autorizar que cada prelado realizase la reforma atendiendo a las particularidades de cada zona.

REFORMA BENEFICIAL EN PALENCIA. LA DIÓCESIS ANTES DE LA REFORMA

El marco territorial que ofrece este estudio se ocupa de la diócesis de Palencia (ver Apéndice IV) que en este momento no coincidía con los límites actuales, esto ocurre a partir de 1955, cuando se hicieron coincidir los límites provinciales, surgidos de la configuración territorial de 1833, con los diocesanos. La diócesis palentina en este momento histórico comprendia parte de tres provincias: Palencia, Valladolid y Santander. De Palencia estaría incluida toda la provincia, salvo el partido de Saldaña, situado en la parte occidental y dependiente de la diócesis de León, y unos pequeños territorios ubicados en la parte oriental de la provincia y pertenecientes a la diócesis burgalesa. La Tierra de Campos vallisoletana era la región de esta provincia incluida en la diócesis objeto de nuestro estudio. Por último, unos pequeños arciprestazgos localizados en torno al Valle de Liébana, eran los territorios santanderinos integrados en nuestra diócesis.

El alto clero secular estaba integrado por los obispos, que gozaban de una posición acomodada con una renta anual media de 500.000 reales de vellón. Durante el período objeto de nuestro estudio ocuparon la sede episcopal seis prelados, todos fueron grandes defensores y difusores de las ideas ilustradas. Habría que destacar la obra del obispo Argüelles, gran ejecutor en la diócesis de las ideas que se estaban defendiendo a nivel nacional. A él debemos la redacción de dos planes de reforma beneficial y la elaboración de un plan de estudios que permitió la incorporación del Seminario Conciliar de San José en la universidad de Valladolid, lo que favoreció una mejor preparación de los alumnos.

El bajo clero palentino, al igual que el de otras diócesis, mantenia un contacto directo con los feligreses y era el consejero y defensor de la población ante los posibles abusos de las autoridades. Muchos de sus miembros destacaban por el atraso y la ignorancia en que vivian, accedian a estos cargos hijos de labradores y artesanos con muy baja o nula instrucción eclesiástica deseosos de alcanzar el puesto que les propor- 
cinara el prestigio social. Constituía un mundo muy variado, integrado por curas, beneficiados y capellanes.

El primer rasgo que debemos apuntar es el excesivo número de beneficiados frente a la carencia casi absoluta de curas propios titulares de su empleo, tan sólo habia 25 en todo el obispado. En el resto de las parroquias la función pastoral la desempañaban curas tenientes, es decir, personas nombradas por el prelado, a las que se asignaba una cantidad por la instrucción y administración de los sacramentos entre los feligreses. Los destinatarios de estos cargos eran beneficiados de la parroquia y la renta que se les adjudicaba para el desempeño de dichas funciones era insuficiente para su manutención.

Los beneficiados formaban un grupo heterogéneo que englobaba diversas situaciones. Se dividian en dos grandes grupos: patrimoniales y simples. Se denominaban beneficios patrimoniales a aquellos que asumian las cartas de la iglesia y las responsabilidades pastorales, en este grupo se incluian todos los que habían recibido órdenes sagradas. Dentro de él habia tres categorías (ver Apéndice 1): presbiteriales o beneficios de Preste, diaconales o beneficios de Evangelio y subdiaconales o beneficios de Epistola. La edad requerida para acceder a cada cargo era haber cumplido 21 años para ser subdiácono, 22 para diácono y 24 para disfrutar de un beneficio de Preste. De las tres categorías, ésta es la única que permitia desempeñar funciones propias de sacerdote. Tras la reforma todos los beneficios serán presbiteriales.

También se consideraban beneficios patrimoniales a los de grados. Para obtenerlo era necesario haber cumplido los 14 años. Sus tareas consistian en ayudar al sacerdote en el altar, cuidar de los ornamentos y la limpieza de la iglesia. Después de la reforma esta tarea la desempañarán legos retribuidos por el párroco.

Los beneficios simples no comportaban ninguna administración, gobierno o jurisdicción, no tenían cargo de cura de almas. Los requisitos para acceder a ellos se limitaban a haber obtenido la primera tonsura, ésta se concebia como una preparación al estado eclesiástico en la que el individuo podia o no continuar. Su condición no le prohibia contraer matrimonio y llevar una vida completamente seglar.

\section{LA PROVISIÓN}

En todos los cargos habia un predominio de la patrimonialidad local, ya fuesen de libre presentación, patronato laico o eclesiástico. Ofrecia la 
ventaja de una mayor compenetración con los feligreses, perto también daba lugar a abusos y a una vocación dudosa, pues algunos estaban más interesados en la obtención de unas rentas - por muy exiguas que fuesen-que en el desempeño de sus funciones.

La mayoría de los beneficios eran de libre presentación, en algunos casos el nombramiento recaía en patronos laicos o eclesiásticos, aunque todos «entre patrimoniales del pueblo».

El acceso a los beneficios se hacía mediante concurso-oposición. Mediante edicto público se convocaba a los naturales de las villas y lugares donde se producia la vacante, concediendo un plazo de quince dias, improrrogables, para solicitar el acceso a la misma. A continuación, también en el término de quince dias, se presentaban las pruebas que atestiguasen reunir los requisitos exigidos en la convocatoria, es decir, poseer la patrimonialidad, tener la edad necesaria y hallarse libre de todo impedimento canónico. Pasado este tiempo, se señalaba dia para el examen. No se tenía en cuenta la vida y costumbres del opositor.

El examen constaba de varias partes, la primera correspondía a una prueba de Gramática, una vez superada ésta daba comienzo la segunda, consistente en la lectura de un texto de Teología, otro de Cánones y un último de Moral.

Concluida esta fase, se adjudicaba el beneficio al candidato más idóneo. Si se hallaban dos o más en la misma situación, se les convocaba a un segundo examen, adjudicando el puesto al que obtuviese mayor puntuación. Si se alcanzaba el mismo resultado, se remitía al prelado para que eligiese al que considerase más apto.

\section{PLANES DE REFORMA}

La reforma beneficial en Palencia comenzó en fechas muy tempranas, pues antes de que existiese una normativa general que marcara las pautas para su ejecución, el obispo Bustamente envió un «Anteproyecto de Reforma Beneficial» al Consejo. En él, el prelado esbozaba la situación de la diócesis, al tiempo que indicaba las posibles modificaciones a realizar.

El mencionado prelado en su informe de 15-4-1760 distinguía tres tipos de beneficios: simples, patrimoniales y curados.

Respecto a los beneficios simples no informaba del número de cargos de esta categoría que había en el obispado, pero aconsejaba reducir 97 , 
destinándolos a dotar curatos pobres, proveer maestros de escuela y de primeras letras, asi como ayuda a las fábricas de iglesias pobres u otros fines piadosos.

En cuanto a los beneficios patrimoniales de los 1155 que habia, proponia la supresión de 126 por temor a la oposición de los pueblos, y dotarlos con una renta anual de 300 ducados.

Por último, en relación a los curatos, el prelado proponia mantener la nutualidad, es decir, la capacidad que tenía el proveedor de nombrar o revocar los cargos. El aumento de dotación se conseguiría uniendo las rentas de varios beneficios.

El fiscal, en su respuesta 13-7-1768 ${ }^{4}$, criticaba aquellas respuestas que no le parecian apropiadas tomar e indicaba las pautas a seguir. Éstas incluian división del obispado en partidos o arciprestazgos, en cada uno se especificaría los pueblos que comprendia; además, era necesario señalar por pueblos los vecinos que lo componian, las iglesias de que constaban y los beneficios que hubiese, indicando naturaleza, obligaciones y rentas de cada cargo.

Aconsejaba también la creación de un curato perpetuo en cada parroquia, con dotación suficiente y provisto por oposición y concurso general diocesano. Implicaba un concurso abierto, frente a los locales establecidos hasta ese momento y defendido por los diferentes prelados. Supresión de todos los beneficios que fuesen necesarios para poder establecer el curato, dotando a este cargo con una renta anual de 300 ducados y de 200 para los beneficios. Por último, se señalarian todas las cargas decretadas para cada puesto. Estas medidas entrarian en vigor a la vacante de los referidos puestos.

Para realizar todo lo encargado por el fiscal, el 22-11-1774, el obispo Argüelles elaboró el Expediente General de Uniones y Supresiones del Obispado de Palencia ${ }^{5}$ (ver Apéndice II), remitiéndolo al Consejo de Castilla junto con un informe el 17-1-1775 ${ }^{\circ}$.

En este primer plan de reforma se establecian todos los beneficios de Preste, suprimiendo las categorias de Evangelio, Epistola y Grados. En adelante todos tendrian la misma renta y obligaciones. Los nuevos cargos

\footnotetext{
"AHN, Cons. Supr., leg. 16.052, "Expediente respectivo a planes Beneficiales de la Diócesis de Palencia. Pieza G».

"Ibidem, "Expediente General de Uniones y Supresiones de Beneficios del Obispado de Palencia. Pieza A».

6 Ibidem, leg. 16.052, "Expediente General sobre erección y dotación de curatos propios, perpetuos y colativos en todas las iglesias del Obispado de Palencia. Pieza C».
} 
implicaban la residencia en el lugar de su creación, siendo necesario nombrar un sustituto en caso de ausencia.

Establecía una renta diferencial de los cargos en función del arciprestazgo donde radicase el beneficio. Esta clasificación respondia a las diferentes comarcas que había dentro de la diócesis. Fijaba una renta de 200 ducados/año para los situados al sur; ésta era la zona que contribuía con diezmos más numerosos y había que remunerar más a sus miembros. La zona norte era la más pobre y los cargos sólo disfrutaban de una renta anual de 60 ducados. En una situación intermedia estaba el páramo cuyos beneficiados disponian de 150 ducados por año. Estas dotaciones eran los ingresos mínimos que debía percibir un eclesiástico, en la práctica algunas eran superiores.

Por último el plan contemplaba el acceso a los cargos. El prelado aconsejaba ciertas variaciones, se respetaba el mismo modelo de examen, pero nombraba él al candidato que considerase más apropiado. Mediante el nuevo sistema el obispo gozaba de una gran libertad en el nombramiento, pues la puntuación obtenida no sería decisiva en la elección del aspirante.

La ausencia de ciertos puntos en este primer plan, como el establecimiento de vicarios perpetuos o la enumeración del número de personas de confesión y comunión que habia en cada localidad, motivó la devolución del proyecto y la redacción de uno nuevo en 1777.

Este Segundo Plan (ver Apéndice iil) suponia una adición al anterior se mantenía la distribución por arciprestazgos y el mismo número de beneficios. La novedad más importante que introdujo fue la creación de vicarios propios titulares de sus empleo con uno o varios beneficiados de la parroquia frente a los cargos amovibles que se mantenian en el proyecto anterior.

\section{CONGELACIÓN DEL PLAN}

El Cabildo nada más tener noticia del plan elaborado por el obispo Argüelles, manifestó al Consejo la inquietud ante la ejecución del mismo, al tiempo que solicitaba su remisión para poder introducir los cambios que estimase oportunos.

En la exposición de motivos, lo primero que criticaba era la supresión, por parte del obispo, de un gran número de beneficios patrimoniales; ésta era perjudicial por varios motivos: primeramente, restaría esplendor a los 
actos religiosos, pero, además, causaría un gran malestar y un hondo pesar entre los naturales al ver como se reducía el número de clérigos en las parroquias $y$, por tanto, la posibilidad de acceder a los cargos. Según el Cabildo no era necesario, pues desde el siglo xvI se estaba produciendo por simple evolución natural.

Igualmente, se oponía a la desaparición de la jerarquia beneficial (Evangelio, Epístola y Grados), al establecimiento de una patrimonialidad genérica y de vicarios perpetuos. Respecto a los vicarios, el Cabildo creía que debian ser amovibles con el fin de poder destituir a los curas ineptos o a los que no cumpliesen con sus obligaciones. El último aspecto que no aceptaba era la modificación que proponia el obispo para acceder a los beneficios.

Postura opuesta al Cabildo fue la que mantuvieron los pueblos. La oposición mantenida por curas y beneficiados fue frecuente pero modesta, su ámbito de acción no sobrepasaba el marco local y las objeciones se referian a problemas concretos de la parroquia a la cual pertenecian, pero en ningún momento pusieron en peligro la ejecución de la obra. Todas estas quejas evidenciaban el malestar existente en los pueblos ante la inactividad de las autoridades diocesanas; las protestas hacian alusión a la provisión de puestos insuficientemente dotados; retraso en el nombramiento de los cargos, estando las parroquias sin clérigos para atenderlas. En la mayoría de los casos no se dio una respuesta puntual y concreta, se contestó con el silencio administrativo o se dejaba para cuando se hiciera el arreglo a nivel diocesano.

El decreto sobre erección de vicarios estuvo retenido en el Consejo durante más de veinte años; la oposición sistemática del Cabildo, tanto a los planes generales como al de la ciudad de Palencia, elaborado por el obispo Mollinedo (como más adelante se indica), previno a la cámara sobre sus verdaderas intenciones. Se planteó la duda sobre si la oposición era en prevención de posibles inconvenientes, o que el cumplimiento de los mismos afectaria negativamente a su mermada economia tratando de impedir su ejecución por todos los medios.

Cuando el Consejo recibió el informe del Cabildo, paralizó el expediente pensando que su puesta en práctica perjudicaría seriamente la diócesis. El descubrimiento de las verdaderas intenciones del Cabildo y las demandas que presentaron los pueblos permitió la aprobación en 1799 del Plan General Diocesano elaborado por el obispo Argüelles en 1777. A pesar de la sanción regia no se pudo ejecutar, pues cuando el nuevo obispo de la diócesis ocupó la sede episcopal, el plan había desaparecido. La elaboración de uno nuevo suplió al ausente. 
Los planes elaborados por el obispo Argüelles no incluian la ciudad de Palencia, pues éste notificó al Consejo que los cargos estaban bien dotados. Sin embargo, la actitud hostil que demostró el Cabildo a la ejecución de los plantes a nivel diocesano impulsaron al obispo Mollinedo a formar un frente común con los curas de la ciudad intentando demostrar que la reforma era necesaria. Por este motivo el prelado elaboró el Plan de reforma beneficial para la ciudad de Palencia.

Este plan hay que entenderlo como una medida de presión de los prelados para agilizar la aprobación del elaborado en 1777 por el obispo Argüelles y retenido por la oposición del Cabildo.

En las iglesias de Palencia, al igual que en las del resto del obispado, la cura de almas estaba desempeñada por tenientes amovibles, y con una renta insuficiente. El Cabildo era el párroco universal de las cinco parroquias de la ciudad y elegía por examen a sus representantes, pudiendo revocarlos cuando lo estimase oportuno.

Las continuas solicitudes por parte de las parroquias, y la oposición intransigente del Cabildo a cualquier cambio que alterase la situación existente produciendo una disminución de la renta, incitó al obispo a la reflexión. Hizo un frente común con los curas contra el Cabildo para demostrar que la reforma era una necesidad. El Auto de $1-8-1788^{7}$ creaba curatos perpetuos e incrementaba la dotación de éstos a 400 ducados anuales y la de los beneficios a 300 ducados/año. En cuanto a la provisión, se regía por las mismas normas marcadas para el resto del obispado.

El Cabildo trató de oponerse a su aprobación a pesar de que el obispo habia convocado a todas las partes interesadas. El plan tardó once años en ser aprobado hasta que el Consejo comprendió que la oposición del Cabildo no tenía ningún fundamento, y que la finalidad era entorpecer el proceso por las pérdidas ecónomicas que su ejecución implicaba.

Tras la desaparición del plan, elaborado en 1777, de nuevo se inició la correspondencia entre el obispado y el Consejo sobre la forma más rápida de poner término a un asunto pendiente desde hacía tanto tiempo.

Antes de realizar el proyecto, el obispo Moyano solicitó de los notarios mayores un informe sobre la situación de la diócesis. Con toda la información recibida redactó el 28-7-1802 el Tercer plan de reforma beneficial

\footnotetext{
7 AHN, Cons. Supr., ley 15.469, "Inventario de consultas particulares, Decretos, órdenes reales y particulares del segundo medio año de 1799 ".
} 
del obispado de Palencia que remitió al consejo con un informe el 30-7$1802^{8}$.

En él lo primero que observamos, respecto a los dos anteriores, es la falta de un estudio por pueblo o por parroquia de la situación beneficial; se limitaba a erigir un curato en cada parroquia, sin señalar la dotación de ninguno de los cargos. Esta se haria en planes separados en los que se analizaria la situación de cada parroquia, imponiendo las rentas, cargas y número de personas que la integrarian según las circunstancias.

Otra diferencia que existía respecto a los planes anteriores era el nombramiento de curatos. Frente a los vicarios que nombró el obispo Argüelles, D. Buenaventura Moyano prefirió el término curato, pues aparte de la diferencia nominal existía otra cualitativa, según la cual podria dar lugar a confusión con los vicarios nutuales que antes desempeñaban este cargo, además de no ser justo que tuviesen un nombre distinto que les hiciese sentir inferiores a los del resto de las diócesis, teniendo que acceder todos a este puesto por los mismos exámenes. Por último, prohibía el reparto de rentas procedentes de beneficios vacantes, las cuales se destinarian como aumento de dotación de los curatos o para reparación de las fincas o casas rectorales.

D. Francisco Arjona, fiscal del Consejo de Castilla, se mostraba muy conforme al plan ejecutado por el obispo Moyano; podría considerarse como un plan modelo que sirviese de patrón para erigir curatos en otras diósesis donde todavía estuviese pendiente, como el arzobispado de Burgos o los obispados de Santander y Calahorra. Fue sancionado por Su Majestad con Real Cédula de 22-6-1803, sobre consulta de 1 de junio ${ }^{9}$.

\section{APLICACIÓN}

El obispo Moyano en 1802, junto con el plan general, remitió los expedientes de diez parroquias en las que establecía fundamentalmente la congrua de los cuartos y, eri algunas ocasiones, detallaba el número de cargos que quedarían en la parroquia. La dotación de estos expedientes fueron aprobados por el Consejo en 1803.

\footnotetext{
${ }^{8}$ AHN, Cons. Supr., leg. 16.052, "Expediente general sobre erección y dotación de curatos. Pieza $1^{\mathrm{a}}$.

${ }^{9}$ AHN, Cons. Supr, Libro de Iglesia 116-E.
} 
El obispo Almonacid continuó con la tarea de su predecesor y elaboró expedientes que fue remitiendo al Consejo. En ellos se apreciaba el aumento considerable con que dotaba a los nuevos curas, pues de disponer antes de realizar los planes de reforma de una renta que en muchos casos no llegaba a los 100 ducados al año, pasaron a disfrutar la mayoría de más de 300.

En 1807 envió a Madrid 41 autos, siendo aprobados por el Consejo. Este mismo año convocó un concurso general para cubrir los puestos vacantes en ese momento. En 1808, de nuevo envió más autos, pero el estallido de la guerra de la Independencia, con las dificultades de comunicación y la captación de correspondencia que hubo por parte de la guerrilla, debió retrasar la aprobación de los mismos. No se produjo hasta 1814.

Como hemos visto en las páginas precedentes, el proceso de transformación que se inició en la Iglesia española tras la firma del Concordato de 1753 y la reforma beneficial que trajo consigo, no significó simplemente unos cambios cuantitativos como reducción del número de cargos, redistribución de la renta... Supuso un cambio mucho más profundo.

Los reformadores intentaron crear un clero que accediese al cargo teniendo como objetivo el servir a la Iglesia y a los fieles. Se trató de unir el oficio y el beneficio, es decir que todas las personas que tuvieran un beneficio eclesiástico desempeñaran unas funciones y no que aspirasen solamente a su obtención por el disfrute de unas rentas.

La cura de almas fue uno de los ejes centrales de la reforma; antes de realizarse ésta su desempeño corria a cargo de personas nombradas y revocadas a voluntad de quien las otorgaba. La adjudicación por oposición que se hizo tras la reforma garantizó una mejor preparación que fomentaria un clero más instruido, preparado y con un deseo de desempeñar aquellas tareas para las que se habia preparado. El otro aspecto fundamental de la reforma fue la dotación de los cargos; se consiguió que todos tuvieran los suficientes recursos económicos para evitar que como complemento a sus ingresos se dedicaran a tareas ajenas a su función pastoral.

El balance final de la obra pensamos que fue positivo. El clero secular que habia antes de la reforma era muy diferente al que surgió después; el clero reformado era titular de su empleo, con unos ingresos que le permitían vivir dignamente y dedicarse por entero a las tareas pastorales. 


\section{APÉNDICE I}

SITUACIÓN BENEFICIAL ANTES DE LA REFORMA ${ }^{10}$

a) . $^{\circ}$ de beneficiados

\begin{tabular}{|c|c|c|c|c|}
\hline ARCIPRESTAZGO & B. PRESTE & B. EVANGELIO & B. EPISTOLA & B. GRADOS \\
\hline Astudillo & 45 & 7 & 6 & 7 \\
\hline Avia de las Torres ....... & 60 & 6 & 4 & 5 \\
\hline Baltanas $\ldots \ldots \ldots \ldots \ldots \ldots \ldots \ldots \ldots \ldots \ldots \ldots \ldots \ldots$ & 30 & 4 & 3 & - \\
\hline Becerril de Campos .... & 35 & 8 & 6 & - \\
\hline 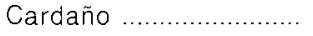 & 1 & - & - & - \\
\hline Carrión de los Condes & 51 & 7 & 6 & 9 \\
\hline Castrejón …..................... & 13 & - & 1 & 3 \\
\hline Castromocho .................. & 40 & 11 & 8 & 7 \\
\hline Cerbatos de la Cueza & 31 & 1 & 8 & 2 \\
\hline Cevico la Torre .............. & 59 & 2 & 1 & 5 \\
\hline 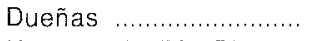 & 40 & 7 & 4 & 4 \\
\hline \multicolumn{5}{|l|}{ Herrera de Río Pisuer- } \\
\hline ga $\ldots \ldots \ldots \ldots \ldots \ldots \ldots \ldots \ldots \ldots \ldots \ldots \ldots \ldots \ldots$ & 48 & 2 & - & 9 \\
\hline Ojeda & 37 & - & - & 7 \\
\hline Ordejón con Redondo & 24 & 3 & - & 7 \\
\hline Paredes de Nava ........ & 60 & 19 & 18 & 9 \\
\hline Peñafiel .......................... & 80 & 5 & 4 & 14 \\
\hline Población de Campos & 45 & 10 & 10 & 3 \\
\hline Polaciones ........................ & 6 & - & - & - \\
\hline Rioseco ........................... & 19 & 8 & 9 & 13 \\
\hline Tordehumos ...................... & 18 & 4 & 3 & 2 \\
\hline Torrelobatón …................. & 16 & 5 & 3 & 10 \\
\hline 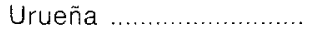 & 15 & 3 & 8 & 2 \\
\hline 5 Vicarias & 16 & 2 & 2 & - \\
\hline TOTAL & 789 & 114 & 104 & 118 \\
\hline
\end{tabular}

${ }^{10}$ AHN, Cons. Supr., leg. 16.052 "Expediente promovido a instancia del Sr. Fiscal (...) sobre la provisión de Beneficios Patrimoniales de este Obispado (...). Años 1758 a 1808”. 
Reforma beneficial en Palencia a fines del Antiguo Régimen

SITUACIÓN BENEFICIAL ANTES DE LA REFORMA

b) Renta media de cada beneficio ${ }^{11}$

\begin{tabular}{|c|c|c|c|c|}
\hline ARCIPRESTAZGO & B. PRESTE & B. EVANGELIO & B. EPISTOLA & B. GRADOS \\
\hline Astudillo & 999,0 & 710,0 & 615,8 & 326,2 \\
\hline Avia de las Torres ...... & $1.034,2$ & 653,8 & 549,2 & 338,6 \\
\hline Baltanas ..................... & 918,6 & 701,2 & 598,0 & - \\
\hline Becerril de Campos .... & $1.748,2$ & $1.049,2$ & 552,0 & - \\
\hline Cardaño & $1.157,0$ & - & - & - \\
\hline Carrión de los Condes & 912,4 & 729,5 & 479,1 & 390,8 \\
\hline Castrejón ........................... & 786,3 & - & 440,0 & 115,6 \\
\hline Castromocho .................. & $1,236,7$ & 921,6 & 579,1 & 180,0 \\
\hline Cerbatos de la Cueza & 870,5 & 541,0 & 784,3 & 378,0 \\
\hline Cevico la Torre ................ & $1.114,6$ & 519,0 & 241,0 & 360,4 \\
\hline 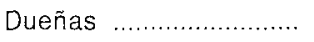 & $1.022,2$ & 703,0 & 573,5 & 458,7 \\
\hline Herrera de Rio Pisuer- & & & - & \\
\hline ga & 909,4 & 629,5 & & 451,3 \\
\hline Ojeda & 549,9 & - & - & 225,8 \\
\hline Ordejón con Redondo. & 567,4 & 321,6 & - & 155,4 \\
\hline Paredes de Nava ......... & $1.793,4$ & 955,5 & 885,7 & 687,7 \\
\hline Peñafiel ……...................... & 990,0 & 616,0 & 790,0 & 239,7 \\
\hline Población de Campos. & 956,6 & 609,7 & 531,9 & 422,0 \\
\hline Polaciones ......................... & 488,3 & - & - & - \\
\hline Ríoseco & $2.245,0$ & $1.722,2$ & $1.747,7$ & $1.895,0$ \\
\hline Tordehumos ..................... & $1.511,7$ & $1.073,5$ & 772,0 & 441,0 \\
\hline Torrelobatón .................. & 919,8 & 605,4 & 547,3 & 271,1 \\
\hline 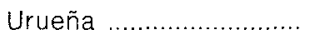 & 703,1 & 656,6 & 229,2 & 276,0 \\
\hline 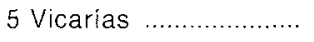 & $1.262,1$ & 870,0 & 766,0 & - \\
\hline … & 1.074 & 768 & 649 & 423 \\
\hline
\end{tabular}

"Todas las rentas van expresadas en reales de vellón. 


\section{APÉNDICE II}

\section{PLAN GENERAL DE $1774^{12}$}

\section{a) Situación beneficial ${ }^{13}$}

\begin{tabular}{|c|c|c|c|c|c|c|c|}
\hline \multirow{3}{*}{ ARCIPRESTAZGO } & \multicolumn{3}{|c|}{$\begin{array}{l}\text { SITUACIÓN ANTES } \\
\text { DE LA REFORMA }\end{array}$} & \multicolumn{4}{|c|}{$\begin{array}{l}\text { SITUACIÓN DESPUÉS } \\
\text { DE LA FEFORMA }\end{array}$} \\
\hline & \multicolumn{2}{|c|}{$N^{\circ}$ BENEFICIOS } & \multirow[t]{2}{*}{ RENTA } & \multicolumn{2}{|c|}{$N^{\circ}$ CARGOS $^{15}$} & \multicolumn{2}{|c|}{ RENTA } \\
\hline & PRESTE & MENORES & & CURA T & BENEF. & CURA T. & BENEF. \\
\hline Astudillo & 48 & 18 & 107.755 & 16 & 43 & 12.615 & 93.516 \\
\hline Avia de las Torres ... & 62 & 11 & 118.394 & 20 & 47 & 16.818 & 101.426 \\
\hline 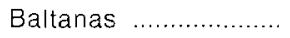 & 35 & 1 & 62.297 & 12 & 25 & 8.094 & 52.247 \\
\hline Becerril de Campos & 35 & 13 & 78.998 & 11 & 30 & 9.900 & 63.659 \\
\hline 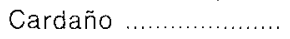 & 1 & - & 1.630 & 1 & 1 & $-{ }^{16}$ & 1.630 \\
\hline 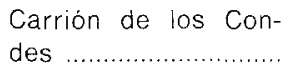 & 51 & 13 & 103.982 & 17 & 41 & 13.242 & 95.072 \\
\hline Castrejón ....................... & 14 & 5 & 24.141 & 10 & 15 & 2.781 & 21.369 \\
\hline $\begin{array}{l}\text { Castromocho } \\
\text { Cerbatos de la....... }\end{array}$ & 43 & 26 & 93.558 & 14 & 40 & 9.806 & 90.876 \\
\hline Cueza. & 33 & 7 & 72.841 & 16 & 29 & 8.851 & 64.762 \\
\hline Cevico la Torre ......... & 58 & 3 & 123.749 & 20 & 47 & 14.598 & 110.409 \\
\hline Dueñas $\ldots \ldots \ldots \ldots \ldots . . . . . . . .$. & 39 & 10 & 98.823 & 12 & 34 & 10.776 & 86.369 \\
\hline 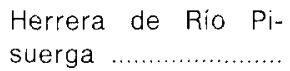 & 50 & 7 & 77.550 & 23 & 39 & 10.499 & 68.717 \\
\hline
\end{tabular}

$12 \mathrm{AHH}$, Cons. Supr., leg. 16.052, «Expediente General de uniones y supresiones de Beneficios del Obispado de Palencia. Pieza A».

13 Todas las rentas están calculadas en reales de vellón.

14 Los datos que en estas columnas se ofrecen no fueron definitivos. Era la propuesta que el obispo Argüelles ofrecia pará mejorar la situación de los cargos que quedaban, y como ya se ha expuesto, este proyecto no llegó a ponerse en práctica.

${ }_{15} \mathrm{E} \mid$ número total de personas que habia en cada arciprestazgo es el que figura en la casilla denominada "Beneficios", pues en la que corresponde a la "Cura Tenencia» se incluyen los beneficiados, que además de las tunciones propias de su oficio desempañaban el de cura teniente. Por ejemplo, en el arciprestazgo de Astudillo el número de beneficiados era de 43 , de los cuales 16 además de beneficiados eran curas tenientes.

${ }^{16}$ En las parroquias donde sólo habia un beneficio, la renta se ofrecía de forma global no especificando qué parte correspondia al beneficio y cuál a la cura tenencia. 
Reforma beneficial en Palencia a fines del Antiguo Régimen

\begin{tabular}{|c|c|c|c|c|c|c|c|}
\hline \multirow{3}{*}{ ARCIPRESTAZGO } & \multicolumn{3}{|c|}{$\begin{array}{l}\text { SITUACIÓN ANTES } \\
\text { DE LA REFORMA }\end{array}$} & \multicolumn{4}{|c|}{$\begin{array}{l}\text { SITUACIÓN DESPUÉS } \\
\text { DE LA REFORMA }{ }^{14}\end{array}$} \\
\hline & \multicolumn{2}{|c|}{$N^{\circ}$ BENEFICIOS } & \multirow[t]{2}{*}{ RENTA } & \multicolumn{2}{|c|}{$N^{0}$ CARGOS $^{15}$} & \multicolumn{2}{|c|}{ RENTA } \\
\hline & PRESTE & MENORES & & CURA T. & BENEF, & CURA T. & BENEF. \\
\hline Ojeda & 40 & 4 & 55.501 & 26 & 36 & 6.386 & 49.835 \\
\hline Ordejón con redondo. & 24 & 10 & 40.411 & 16 & 25 & 6.009 & 34.002 \\
\hline Paredes de Nava ...... & 60 & 40 & 175.125 & 14 & 63 & 14.558 & 151.645 \\
\hline $\begin{array}{l}\text { Peñafiel ................... } \\
\text { Población }\end{array}$ & 80 & 11 & 135.337 & 36 & 60 & 10.323 & 125.556 \\
\hline Campos. & 99 & 20 & 214.430 & 27 & 82 & 28.627 & 185.029 \\
\hline Polaciones .................. & 6 & - & 6.930 & 6 & 6 & - & 6.930 \\
\hline 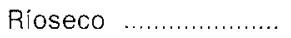 & 23 & 23 & 68.051 & 9 & 29 & 5.684 & 106.680 \\
\hline Tordehumos ............... & 18 & 6 & 51.071 & 5 & 19 & 6.366 & 50.018 \\
\hline Torrelobatón & 17 & 13 & 41.048 & 11 & 16 & 4.436 & 39.049 \\
\hline 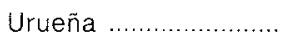 & 15 & 7 & 27.531 & 6 & 14 & 2.606 & 24.950 \\
\hline Vicarias en Campos. & 17 & 6 & 47.676 & 5 & 16 & 5.678 & 42.173 \\
\hline
\end{tabular}




\section{APÉNDICE III}

\section{PLAN GENERAL DE $1777^{17}$}

a) Situación beneficial ${ }^{18}$

\begin{tabular}{|c|c|c|c|}
\hline ARCIPRESTAZGO & N. VICARIOS & N. BENEFICIOS & RENTA VICARIOS \\
\hline 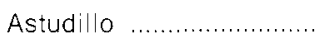 & 14 & 29 & 44.905 \\
\hline Avia de Las Torres ....... & 17 & 30 & 45.896 \\
\hline 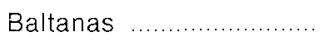 & 12 & 13 & 33.336 \\
\hline Becerril de Campos ...... & 10 & 20 & 26.526 \\
\hline Cardaño .............................. & 1 & - & 1.730 \\
\hline Carrión de los Condes.. & 17 & 24 & 60.286 \\
\hline 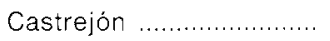 & 9 & 5 & 15.168 \\
\hline Castromocho $\ldots \ldots \ldots \ldots \ldots$ & 13 & 27 & 34.427 \\
\hline Cerbatos de la Cueza ... & 16 & 13 & 42.777 \\
\hline Cevico La Torre .............. & 20 & 28 & 59.571 \\
\hline 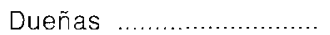 & 11 & 23 & 40.025 \\
\hline Herrera de Río Pisuerga. & 22 & 17 & 45.744 \\
\hline Ojeda & 22 & 10 & 36.754 \\
\hline Ordejón con Redondo ... & 16 & 9 & 29.757 \\
\hline Paredes de Nava ........... & 12 & 51 & 39.125 \\
\hline 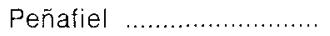 & 36 & 24 & 89.388 \\
\hline Población de Campos ... & 21 & 61 & 63.482 \\
\hline Polaciones ….................... & 6 & - & 6.930 \\
\hline Ríoseco & 6 & 23 & 33.000 \\
\hline Tordehumos ........................ & 6 & 13 & 21.812 \\
\hline Torrelobatón & 12 & 5 & 31.621 \\
\hline Ureña ............. & 6 & 8 & 13.116 \\
\hline Vicarías en Campos ...... & 4 & 12 & 16.021 \\
\hline
\end{tabular}

17 AHN, Cons. Supr., L. 16.052, «Pieza 3." del Expediente General sobre erección de curatos. Año $1777 \%$.

${ }^{18}$ Todas las rentas van expresadas en reales de vellón. 